\title{
Los fondos documentales de la Audiencia Escolástica de la Universidad De Salamanca: POSIBILIDADES Y LÍNEAS dE INVESTIGación
}

\author{
The documentary Scholastic Audience of the University of Salamanca: \\ possibilities and lines of research
}

Gustavo Hernández SÁnCHeZ

Universidad de Salamanca

gustavohistoria@usal.es

Fecha de recepción: 23-VII-2012

Fecha de aceptación: 31-VIII-2012

Resumen: El artículo estudia las posibilidades de investigación de los Fondos documentales de la Audiencia Escolástica del Archivo Universitario Salmantino, recientemente catalogados (2010) -segunda mitad del siglo XVI y primeros años del XVII-. Propone además algunos temas de investigación, dentro de las líneas desarrolladas en el estudio de las universidades de Antiguo Régimen: en el ámbito de las relaciones de poder y la vida cotidiana, y en el de los estudios comparados, a partir de los trabajos realizados en otras universidades; como forma de contribuir al desarrollo de la investigación y conservación de nuestro patrimonio histórico, adjunta la transcripción de un pleito-tipo.

Palabras clave: Audiencia Escolástica, Universidades de Antiguo Régimen, relaciones de poder, vida cotidiana, estudios comparados.

AвSTRACT: This article reviews the research possibilities of the recently catalogued (2010) Collection of documents from the Scholastic Audience in the University of Salamanca's Archive for the second half of the sixteenth century and early years of the seventeenth century, recently cataloging (2010). It also puts forward some research topics along the lines developed in the study of classical Old Regime universities in the field of power relations and everyday life and in the comparative studies, based on the work at other universities, as a contribution to the development of the research and conservation of our heritage. Find also attached the transcription of a lawsuit-type. 
Keywords: Scholastic Audience, Old Regime universities, power relations, everyday life, comparative studies.

\section{INTRODUCCIÓN}

El presente artículo se propone introducir las posibilidades de investigación de los fondos documentales de la Audiencia Escolástica del Archivo Universitario Salmantino como base para futuros trabajos y eje de nuevas líneas de investigación dentro de las seguidas en los últimos años en la Historia de las Universidades de Antiguo Régimen.

El carácter novedoso del estudio viene marcado por la reciente catalogación de los fondos citados, que comenzó las labores de «limpieza, ordenación, foliación y descripción ${ }^{1} »$ el pasado año 2010 . Hasta entonces pocos o casi ningún investigador habían tenido acceso a unos fondos que muestran, a partir de las primeras aproximaciones llevadas a cabo, la posibilidad de abrir y renovar desde el punto de vista historiográfico, no solo la historia de la Universidad de Salamanca, sino también de las universidades espańolas e hispanoamericanas de Antiguo Régimen, en el ámbito de los estudios comparados.

La única limitación que, hasta la fecha, poseen los fondos de la Audiencia Escolástica, es la del trabajo avanzado, que de momento solo cubre la segunda mitad del XVI y primeros años del XVII. Esperemos que en los próximos años la catalogación de dichos fondos continúe, y estas líneas sean solamente los primeros pasos.

Este estudio, en definitiva, tiene la suerte de ser una de las primeras aproximaciones investigadoras en un campo historiográfico, el de la Historia de las universidades de Antiguo Régimen, del que, aunque suene tópico, todavía queda mucho por descubrir y aclarar.

\section{ESTADO DE LA CUESTIÓN: UN VACÍO HISTORIOGRÁFICO}

El hecho de ser un fondo de reciente catalogación implica la existencia de un vacío historiográfico que se venía denunciando desde hacía tiempo. Más allá de algunas referencias aquí y allá, encontramos tan solo la obra de María Paz Alonso Romero, en la historia del derecho, como trabajo específico sobre dichos fondos ${ }^{2}$. Si bien la propia

Universidad de Salamanca: Servicio de Archivos. Memoria del Servicio de Archivos correspondiente al curso 2009-2010. p. 41. Disponible en: http://campus.usal.es/-memoria/0910/11_rectorado/11_7_archivo_universitario.pdf [consultado 14/04/2012]. En este punto, cabe destacar la buena gestión realizada por el equipo a cargo del director del Archivo Universitario Salmantino (Miguel Ángel Jaramillo).

2 ALONSO ROMERO, Ma. Paz. Universidad y sociedad corporativa. Historia del privilegio jurisdiccional del estudio salmantino. $1^{\text {a }}$ Ed. Madrid: Technos, 1997. 
autora reclama la necesidad de investigaciones en la línea de las diversas hipótesis que plantea. Nosotros plantearemos algunas otras.

Se hacen necesarias, por tanto, obras de contexto que abrirían las posibilidades, tanto en el trabajo realizado en los últimos ańos por los especialistas en historia de las universidades en Salamanca, como en otras, esto es, imitar lo realizado ya en otras universidades y/o ampliar dichas investigaciones en el ámbito de los estudios comparados ${ }^{3}$.

Entre las obras de contexto, haremos referencia a la obra de George Haley, que hasta el momento había sido casi el único testimonio directo, de grandísimo valor, por cierto, sobre la vida cotidiana de los estudiantes del momento. Transcribe e introduce el diario que Girolamo da Sommaia, estudiante florentino, dejó como testimonio único; o el breve estudio de Luis Enrique Rodríguez San Pedro-Bezares sobre el diario de Gaspar Ramos Ortíz .

Sobre cuestiones generales del Estudio salmantino, cabe citar la obra coordinada por Luis Enrique Rodríguez San-Pedro Bezares y Juan Luis Polo Rodríguez 5 . Incluye un Estado de la cuestión actualizado a fecha de 2009 y una recopilación bibliográfica cuyas obras más significativas no es preciso repetir aquí. No obstante, aquellas más específicas que nos han parecido interesantes aparecerán citadas a lo largo del presente trabajo.

3 Una introducción actualizada sobre el panorama historiográfico ibérico referido a la historia de las universidades: TORREMOCHA HERNÁNDEZ, Margarita. «Nuevos enfoques en la historia de las universidades: la vida cotidiana de los universitarios en la península ibérica durante la Edad Moderna» en Chronica Nova, no 35, 2009, pp. 193-219.

4 HALEY, George. Diario de un estudiante de Salamanca. La crónica inédita de Girolamo da Sommaia (1603-1613). Edición e introducción de George Haley. 1a ed. Salamanca: Universidad de Salamanca, 1977; RODRÍGUEZ-SAN PEDRO BEZARES, Luis Enrique. Vida, aspiraciones y fracasos de un estudiante de Salamanca: el diario de Gaspar Ramos Ortiz, 1568-1569. 1a ed. Salamanca: Universidad de Salamanca, 1987. El trabajo avanzado en nuestra investigación nos lleva, en cambio, a cuestionar la pertinencia de obras como la de CORTÉS VÁZQUEZ, Luis. La vida estudiantil en la Salamanca clásica a través de los textos. $1^{\text {a }}$ ed. Salamanca: Universidad de Salamanca, 1985, basada en la tradición literaria y de innegable valor cultural. Estudios posteriores tendrán que aclarar si dicha tradición se corresponde con la documentación existente. Otras referencias sobre la vida cotidiana de los universitarios salmantinos serán citadas a lo largo del artículo.

5 RODRÍGUEZ-SAN PEDRO BEZARES, L.E. y POLO RODRÍGUEZ, J. L. (coords.) Historia de la Universidad de Salamanca. Vol. I. Trayectoria histórica e instituciones vinculadas. Vol. II. Estructuras y flujos. Vol. III. 1 y 2 Saberes y confluencias. Vol. IV. Vestigios y entramados. $1^{a}$ ed. Salamanca: Universidad de Salamanca: 2002, 2004, 2006 y 2009. Son también de interés las siguientes obras: RODRÍGUEZ CRUZ, Águeda M. Historia de la Universidad de Salamanca. 1a ed. Salamanca: Fundación Ramón de Areces-Congregación de Santo Domingo, 1990; o la editada por ÁLVAREZ FERNÁNDEZ, Manuel, ROBLES CARCEDO, Laureano y RODRÍGUEZ-SAN PEDRO BEZARES, Luis Enrique. La Universidad de Salamanca. I. Historia y Proyecciones. II. Docencia e investigación. III. Arte y Tradiciones. 4a ed. [1 a ed. de 1972]. Salamanca: Ediciones Universidad de Salamanca, 1989, 1990, 1990. En último lugar, citaremos el excelente resumen de la profesora Ana Carabias: CARABIAS TORRES, Ana María. "La Universidad de Salamanca en la Edad Moderna» en MARTÍN, José Luis (Dir.) Historia de Salamanca. t. III. Edad Moderna. coord. Por Ángel Rodríguez. 1ª ed. Salamanca: Centro de Estudios Salmantinos, 1999. pp. 375-474. 


\section{POSIBILIDADES: HISTORIA DE LAS UNIVERSIDADES DE ANTIGUO RÉGIMEN}

En este punto, hay que destacar, en primer lugar, la labor realizada por el Centro de Historia Universitaria Alfonso IX (CHUAIX) de la Universidad de Salamanca, desde dos puntos de vista: temas y lugares de estudio.

Los primeros estarían relacionados con las posibilidades intrínsecas de los fondos que describimos. Los segundos con las posibilidades que el estudio de dichos fondos abriría en el marco de los estudios comparados.

Entre los temas (o líneas de investigación fundamentales), Luis Enrique Rodríguez San-Pedro Bezares clasifica los más trabajados por la historiografía de los últimos veinte años ${ }^{6}$ :

- Poderes y financiación: gobierno y poderes universitarios, hacienda y financiación de las universidades.

- Disciplinas y saberes: pedagogía y régimen docente, contenidos de las disciplinas.

- Estudiantes y profesores: aspectos sociales, poblaciones escolares, graduaciones, prosopografía académica y vida estudiantil cotidiana.

- Patrimonio y tradiciones: ceremonias y festejos, aspectos patrimoniales y artísticos, exposiciones.

- Instituciones vinculadas y figuras destacadas.

Respecto a los lugares, el trabajo citado también alude a los grupos y centros de investigación, tanto dentro del país, ya hicimos referencia al CHUAIX, como fuera, en Europa (Bolonia y Coímbra) e Iberoamérica (México) dónde también existen otros centros de estudio de Historia Universitaria ${ }^{7}$.

6 RODRÍGUEZ-SAN PEDRO BEZARES, L. E. «Salamanca y las Universidades Hispánicas. Etapa Clásica, siglos XV-XVIII» en RODRÍGUEZ-SAN PEDRO BEZARES, L. E. y J. L. Polo Rodríguez. Historia de la [...] op. cit. p, 2. pp. 329-387.

7 Instituto Nebrija de Estudios sobre la Universidad, de la Universidad Carlos III de Madrid. Centro de Estudios sobre la Historia de las Universidades de la Universidad de Valencia. Centro Interuniversitario per la Storia delle Universitá Italiane (CISUI) de la Universidad de Bolonia. Instituto de Investigaciones sobre la Universidad y la Educación (IIUSE) de la Universidad Nacional Autónoma de México (UNAM), etc. La coordinación del trabajo de dichos centros puede dar, y de hecho está dando, buenos frutos. Sirva de ejemplo el monográfico sobre «Universidades clásicas de la Europa Mediterránea: Bolonia, Coímbra y Alcalá» en Miscelánea Alfonso IX, 2005. Centro de Historia Universitaria. Salamanca: Universidad de Salamanca, 2005. 


\section{LOS FONDOS DOCUMENTALES DE LA AUDIENCIA ESCOLÁSTICA}

Del trabajo avanzado (primeras aproximaciones) en la consulta de los fondos documentales de la Audiencia Escolástica, podemos concluir que hay dos tipos fundamentales de documentos: expedientes judiciales y autos judiciales (o pleitos). Comentémoslos brevemente antes de hacer una propuesta de líneas de investigación (o temas de estudio).

\subsection{EXPEDIENTES JUDICIALES}

Los expedientes judiciales recogen por escrito las actuaciones que se van sucediendo en un proceso judicial.

Las series de los expedientes judiciales catalogadas cubren la segunda mitad del XVI y primer tercio del XVII, según indica el siguiente cuadro.

\begin{tabular}{|l|l|l|}
\hline & Serie & Fechas \\
\hline & & \\
Audiencia & Expedientes Judiciales & $1547-1566 ; 1590-1596 ; 1597,1598 ;$ \\
Escolástica & & $1599 ; 1599-1600 ; 1600 ; 1601 ; 1602 ;$ \\
& & $1603 ; 1604 ; 1605 ; 1606 ; 1607 ; 1608 ;$ \\
& & $1609 ; 1610 ; 1611 ; 1612 ; 1613 ; 1614 ;$ \\
& & $1615 ; 1616 ; 1617 ; 1618 ; 1619 ; 1620 ;$ \\
& & $1621 ; 1622 ; 1623 ; 1624 ; 1625 ; 1626 ;$ \\
& & $1627 ; 1629 .$. \\
\hline
\end{tabular}

Cuadro 1. Series de Expedientes Judiciales Catalogados. Cuadro de elaboración propia.

\subsection{Autos Judiciales}

Los autos judiciales son formas de resoluciones judiciales, fundadas, que deciden sobre cuestiones secundarias, previas, incidentales o de ejecución, para las que no se requiere sentencia.

La serie sobre Autos Judiciales es más numerosa pero menos voluminosa (de 900 documentos catalogados aproximadamente, solo unos 100 corresponden a Expedientes Judiciales; el resto son, por lo general, Autos). Los Autos Judiciales suelen ser más bre$v^{8}{ }^{8}$. Aparecen en diferentes secciones dependiendo de la instancia en la que se resuelvan:

8 El por qué lo da ALONSO ROMERO, Ma . Paz «Teoría y praxis en la enseńanza del derecho: tratados y prácticas procesales en la Universidad de Salamanca a mediados del siglo XVI» En Anuario de historia del derecho español. Documentos para la historia del derecho español. Madrid: Ministerio de Justicia, 1991. pp. 451-547. Como explica la autora, el tratamiento de los casos es más dinámico para aligerar el trabajo, es decir, se resuelven en menos tiempo y, por lo general, 
la del maestrescuela (los casos juzgados por el Juez del Estudio o Juez Ordinario del Estudio -conocido como Juez Escolástico o Juez Académico a partir de 1505-; autoridad delegada de la dignidad de la maestrescolía catedralicia, sobre la que recae la tarea de impartir justicia entre los aforados universitarios), rector, claustro de diputados, claustro de rector y consiliarios, o administrador; las dos primeras son las que más se repiten.

\section{LÍNEAS DE INVESTIGACIÓN Y EJEMPLOS HISTÓRICOS: DE LO COTIDIANO A CUESTIONES GENERALES DE PODER}

Las líneas de investigación que dicha documentación proporciona, según nuestro punto de vista, y de acuerdo a la propuesta de los especialistas antes señalados, son: en primer lugar y más evidente, la que se refiere a cuestiones de la historia de la vida cotidiana y cultura material del Estudio. Tal vez esta línea de investigación no sea la más importante más allá del contexto o el relato del detalle, pero sí resulta interesante de acuerdo a las nuevas tendencias historiográficas ${ }^{9}$. En segundo lugar, hemos querido destacar, y por eso aparece primero, las cuestiones referentes a poder.

Ambas líneas de investigación, a su vez, pueden aparecer analizadas intra o extramuros, es decir: viendo cómo se relacionan los estudiantes entre sí (intramuros) o cómo se relaciona el estudio, y sus miembros, con la ciudad y sus vecinos y vecinas (extramuros). De este modo, las posibilidades comienzan a ampliarse de forma considerable.

Igualmente, las cuestiones de poder tienen, por un lado, carácter interno: entre poderes de la propia universidad; y, por otro, externo: en este caso, la delimitación del poder del fuero académico frente a otros poderes locales sería la más inmediata, pero también a mayor escala, la intervención regia y/o pontificia en el Estudio, que nos conduce a conocidos debates historiográficos sobre la primacía de un poder o de otro, resulta muy interesante. A partir de aquí, las posibilidades siguen ampliándose, encontrando en los estudios comparados múltiples y continuas diversificaciones. A continuación, citaremos algunos ejemplos con los que nos hemos encontrado.

\subsection{EXPEDIENTES JUdICIALES}

En cuanto a los Expedientes judiciales, documentos que hacen referencia al desarrollo de los diferentes procesos y pleitos, los temas de estudio que podemos extraer son

suelen ser más breves. Adjuntamos, como ejemplo, la transcripción de un pleito-tipo.

9 Así lo indica HERNÁNDEZ SANDOICA, Elena. Tendencias historiográficas actuales. Escribir historia hoy. $1^{a}$ ed. Madrid: Akal, 2004. p. 437 y ss. Véase también el clásico de POUNDS NORMAN, J.G. La vida cotidiana: historia de la cultura material. $1^{\text {a }}$ Ed. en castellano. Barcelona: Crítica, 1992. [Herat and Home. A History of Material Culture. $1^{\text {a }}$ Ed. en inglés. Bloomington: Indiana University Press, 1989]. 
los mismos, con la dificultad de que se encuentran desordenados en diversas informaciones (informaciones sobre limpieza de sangre, ocupación de vacantes, etc.) sentencias (que pueden hacer referencia a procesos y pleitos contenidos en los mismos Expedientes Judiciales o no) e, incluso, como acabamos de mencionar, procesos y pleitos. Adjuntamos la transcripción de algunos fragmentos contenidos en el pleito que en 1562 mantuvieron el bachiller de la Torre y el licenciado Meneses, sobre hora de lectura; un caso, el de la disputa entre maestros sobre las horas de lectura, muy repetido.

\subsection{Pleitos}

En cuanto a los pleitos, justificaremos las líneas de investigación descritas a través de algunos ejemplos que podríamos denominar significativos, de acuerdo al concepto propuesto por Guinzburg y la historiografía italiana de «excepcional normal ${ }^{10} »$ :

\section{Cuestiones relativas a poder}

\section{Jurisdicción}

Es el caso del pleito entre el Maestro de ceremonias Francisco de Vargas con Francisco de Barrientos, escribano de la Audiencia Episcopal, sobre la jurisdicción que ha de juzgarle por la reclamación que le hace de una deuda ${ }^{11}$ (1604), en el que uno pretende acogerse a los «estatutos y privilegios» que ofrece el fuero estudiantil para que «cualquier persona que algo me quiera pedir a de venir a demandallo en este tribunal»-el del la Audiencia Escolástica- y el otro reclama «reponer y remitir la causa a la justiçia seglar ${ }^{12}$ ». Ambos exponen sus razones.

Este pleito es un claro ejemplo de las cuestiones sobre límites entre jurisdicciones y los debates sobre a quiénes alcanza el régimen jurídico específico del Estudio, ya que su carácter más benevolente respecto a los acusados causaba numerosos problemas y hacía que muchos quisiesen acogerse a él.

\section{Cuestiones sobre deudas y pagos}

Se trata de los más abundantes; tanto es así que copan en torno al $80 \%$ de los pleitos catalogados. No obstante, entre ellos se cuelan datos a partir de los cuales podremos esgrimir cuestiones interesantes relacionadas con el poder. Estudiemos un par de ejemplos:

10 Utilizamos el concepto del «excepcional normal» para indicar que la documentación citada no es la más numerosa y, en cambio, trae a colación cuestiones importantes que permiten profundizar y/o aclarar, como venimos apuntando, temas de interés para la historiografía. JUSTO SERNA, Alonso y Anaclet Pons. "La microhistoria: instrucciones de uso» en Cómo se escribe la microhistoria: ensayo sobre Carlo Guinzburg. 1a Ed. Madrid: Cátedra, 2000. pp. 231-273.

11 AUSA 3016,7. Otros documentos que muestran cuestiones de jurisdicción-enfrentamiento entre distintas autoridades y fueros: Médico con Alguacil mayor de Salamanca sobre la devolución de la rodela que le quitó una noche yendo a visitar enfermos. AUSA 3018,3.

12 AUSA 3016, 7. fol. 4. r. 
El primero son los Embargos hechos de los préstamos y rentas del maestrescuela por el deán y cancelario de la catedral «en este año de sesiscientos y catorce ańos y renta de lo que cupo en el año de seiscientos y treçe ${ }^{13}$ ". A través de este tipo de pleitos puede abordarse el estudio de la naturaleza jurídica del maestrescuela, y de las personas en quién delegaba sus funciones, en sus dos acepciones: la de juez escolástico y la de juez secular; así como las cuestiones que se refieren a su jurisdicción y los límites de su poder.

El segundo caso seleccionado es el del pleito entre los acreedores del catedrático Diego Espino de Cáceres, catedrático jubilado y fallecido en 1599, sobre la asignación de su congrua y el pago a éstos ${ }^{14}$ (1603). En este caso el pleito es mucho más voluminoso, ya que los acreedores no eran pocos; el juez del Estudio aparece aquí como mediador.

Algunos de estos pleitos pueden arrojar también información sobre la hacienda y la financiación, como son los numerosos pleitos sobre el pago de tercias, novenos, diezmos y otros impuestos (todos de carácter eclesiástico). Sin embargo, podemos incluirlos mejor en el apartado sobre jurisdicción, ya que lo que en ellos en realidad se dirime es a qué jurisdicción territorial o institución corresponde el cobro de dichos impuestos ${ }^{15}$.

\section{Cuestiones protocolarias y de precedencia}

Abundan también litigios entre catedráticos sobre precedencia, o cuestiones protocolarias; disputas que nos ponen sobre la pista de la importancia de unas Facultades u otras, unos maestros, adscritos a determinado grupo de poder (colegiales, órdenes o manteístas -si es que éste último grupo representase algún grupo de poder-), u otros. También sobre el régimen de funcionamiento interno de la Universidad de Salamanca.

Es un buen ejemplo el proceso entre los maestros Diego Rodríguez, teólogo, y Fray Luis de León, maestro de teología, sobre la asignación de hora y lectura en teología ${ }^{16}$ (1577). En dicho pleito el maestro Fray Luis de León llega a apelar al rey y Consejo real (obtiene una Real provisión), la cual presenta en el pleito, que termina por resolverse ante el Claustro pleno.

Lejos de las vicisitudes cotidianas relacionadas con la idiosincrasia de los catedráticos, en pleitos de este tipo se dirimen cuestiones tanto más importantes, que pueden dar pie a contrastar o no las hipótesis planteadas por autoras como M. Paz. Alonso: en primer lugar, la más inmediata de que «el Consejo Real supervisa y controla la vida universitaria y declara y fija su régimen jurídico (...) aspecto poco tratado por la historiografía, que

\footnotetext{
13 AUSA 3676,6. fol. 1. r.

14 AUSA 3013,2.

15 Los ejemplos son numerosos.

16 AUSA 3000,16.
} 
prefiere hablar de una Universidad puesta al servicio de los monarcas ${ }^{17}$; y en segundo lugar, cuestiones de debate historiográfico acerca de la primacía del patronato regio -sobre la que se basa la propuesta interpretativa de la autora- o pontificio en las universidades del Antiguo Régimen.

\section{Vida cotidiana}

Es la parte, por decir de alguna manera, más ligera, la que nos permitirá recrearnos en el detalle para ver de cerca la vida cotidiana del estudiante de la segunda mitad del XVI y principios de XVII, tanto dentro del Estudio como fuera de él. Tal vez los más impactantes sean los relacionados con los siguientes tres ejemplos:

\section{Casos de injuria}

Como el del Médico vecino de Aguilar de Campos con estudiante de cánones sobre haberle injuriado a él y a su hijo llamándolos judíos ${ }^{18}$; que pueden ponernos en la pista de las relaciones entre los estudiantes y los vecinos y vecinas de la ciudad.

\section{Casos de violencia}

Como el caso de El fiscal de la Audiencia Escolástica con estudiantes sobre los incidentes con armas ocurridos al salir de la exposición del colegial del mayor de Cuenca, licenciado Mejía, opositor a cátedra de leyes ${ }^{19}$ (de 1601) y en la que, de acuerdo a varios testigos presenciales, en el mismo patio de escuelas:

«empezaron a hechar manos a espadas, troqueles, alfanges y dagas y otras armas y se empeçaron a acuchillar y salieron acuchillandose de las dichas escuelas por la puerta que sale a la yglesia mayor hacia San Sebastian como quarenta o cinquenta hombres ${ }^{20}{ }_{\%}$.

Este tipo de casos nos ofrecen una visión que, si bien no es habitual, pues no todos los estudiantes -cuya figura podríamos asemejar mejor a la de un clérigo- andaban en estos menesteres, la historiografía de los últimos años, en cambio, ha querido

17 ALONSO ROMERO, Ma. Paz. Universidad y sociedad corporativa [...] Op. cit. p. 2. p. 18. Si bien autoras como Ana Carabias ya adelantaron esto hace tiempo: «Basándonos en estos hechos, podemos decir que el poder monárquico se impone sobre las universidades españolas rompiendo definitivamente el equilibrio medieval entre ambas potestades». En CARABIAS TORRES, Ana María. «La legislación universitaria en el siglo XVI» en Revista Española de Derecho Canónico, vol. 43, no 120, 1986, pp. 101-120, p. 102.

18 AUSA 3008, 14. El estado de conservación de éste documento es catastrófico. Aún no hay microfilmación.

19 AUSA 3008, 15. Otro de violencia: Estudiante con el corregidor del Puente del Arzobispo sobre aberle apresado con motivo de las heridas sufridas por (...un) clérigo, por lo que solicita inhibitoria. AUSA 3010,19.

20 AUSA 3008, 15. fol 2. v. 
destacar; lo mismo que los casos de aquellos que, aunque siendo clérigos, transgredían las normas ${ }^{21}$.

Este tipo de casos podríamos enmarcarlos dentro de las relaciones intramuros del estudio; no siempre tan pacíficas como habría de esperarse de acuerdo con un oficio de tal dignidad. Otros casos llevarán este tipo de relaciones conflictivas a la ciudad.

\section{Sexo}

Como el pleito de una Vecina con estudiante sobre el reconocimiento de un hijo que tuvo como suyo y el pago de los daños y gastos que tuvo ${ }^{22}$ (de 1602). Ésta anécdota nos pone en contacto con las relaciones entre estudiantes y vecinos y vecinas de la ciudad. En esta ocasión, un «estudiante deste estudio a mucho tiempo que esta amanzebado con Ynes del Castillo la qual a parido» produciéndose «escándalo y murmuracion ${ }^{23}$ ».

...Pero también existen muchos otros, los cuales se pueden consultar fundamentalmente, como ya indicamos antes, a través de las cuestiones sobre deudas y pagos; y que, lejos de mostrarnos una sociedad tan conflictiva, nos permitirán abordar la verdadera realidad del estudiante en su cotidianeidad. Ofrecemos una selección de los temas que más se repiten: probanzas, medicina, alimentación, vivienda, vestido, oficios (arte, música, religión), servicios, transportes o herencias ${ }^{24}$.

21 Los más conocidos son los de: TORREMOCHA HERNÁNDEZ, Margarita. La vida estudiantil en el Antiguo Régimen. $1^{\text {a }}$ ed. Madrid: Alianza, 1998. para la Universidad de Valladolid; y PESET, José Luis y HERNÁNDEZ SANDOICA, Elena. Estudiantes de Alcalá. $1^{\text {a }}$ ed. Madrid: Comisión de Cultura del Excmo. Ayuntamiento de Alcalá de Henares, 1983. para la Universidad de Alcalá. Recoge una valiosísima información sobre el tema que tratamos: RUÍZ TORRES, Pedro (coord.). Doctores y escolares. II Congreso Internacional de las Universidades Hispánicas (Valencia, 1995). Vol. I y II. 1 ${ }^{\text {a }}$ ed. Valencia: Universitat de València, 1998. Otros estudios interesantes sobre la vida cotidiana del estudiante salamantino del Antiguo Régimen, además de los ya citados, son: RODRÍGUEZ-SAN PEDRO BEZARES, Luis Enrique. "Vida estudiantil en el Antiguo Régimen» en Miscelánea Alfonso IX, 2001. Centro de Historia Universitaria. Salamanca: Universidad de Salamanca, 2002, pp. 69-96, en un monográfico sobre Vida Estudiantil en el Antiguo Régimen; o los más novedosos de CARABIAS TORRES, Ana María; LORENZO PINAR, Francisco Javier y MOLLER RECONDO, Claudia. Salamanca: Plaza y Universidad. $1^{a}$ ed. Salamanca: Universidad de Salamanca, 2005; y RODRÍGUEZ-SAN PEDRO BEZARES, Luis Enrique y WERUAGA PRIETO, Ángel. Elogios triunfales. Orígenes y significado de los vitores universitarios salmantinos (ss. $X V-X V I I I) .1^{\text {a }}$ ed. Salamanca: Universidad Pontificia de Salamanca, 2011. Un interesantísimo trabajo de erudición, lo ofrece el profesor RODRÍGUEZ-SAN PEDRO BEZARES, Luis Enrique. Atmósfera universitaria en Cervantes. $1^{\text {a }}$ ed. Salamanca: Universidad de Salamanca, 2006.

22 AUSA 3012,20. Otro documento sobre cuestiones amorosas entre estudiantes y vecinas de la ciudad: Vecina de Salamanca con zapatero para declarar nulo su matrimonio. AUSA 3019,10. AUSA 3012,20. fol 2. r.

24 Servirían para completar la serie de la multitud de trabajos dispersos sobre cuestiones referentes a la vida cotidiana de los universitarios salmantinos del Antiguo Régimen. Recogemos algunos de ellos: MARCOS RODRÍGUEZ, Florencio. "Un pleito de don Pedro Calderón de la Barca estudiante en Salamanca» en Revista de Archivos, Bibliotecas y Museos, LXVII, 2, 1959, pp. 717-731.; RODRÍGUEZ-SAN PEDRO BEZARES, Luis Enrique. «Estudiantes en Salamanca 


\section{Instituciones vinculadas}

En último lugar, también consideramos importante citar los casos en los que se producen detenciones. Dicha documentación nos puede llevar a tratar la cárcel del estudio y compararla, por ejemplo, con las prisiones locales o las cárceles de otras universidades modernas.

Y de nuevo, si siguiésemos cuestiones más generales, en la línea de los historiadores del derecho - destacando el trabajo iniciado por $\mathrm{M}^{\text {a }}$ Paz Alonso-, a estudiar el fuero estudiantil y sus características, implicaciones y límites.

\section{CONCLUSIONES}

En definitiva, las primeras aproximaciones a los Fondos de la Audiencia Escolástica del Archivo Universitario Salmantino abren las posibilidades de investigación de la historia universitaria en la Edad Moderna; trabajo que parecía concluido después de la obra coordinada por Luis Enrique Rodríguez-San Pedro Bezares y Juan Luis Polo Rodríguez (a quienes agradezco su guía y buenos consejos en la realización de la investigación), no solo en el ámbito de los estudios comparados, como ya apuntaban ellos.

Por tanto, las líneas de investigación (o temáticas de estudio) que podemos proponer a través de los legajos consultados, son las siguientes:

- Cuestiones relativas a poder: jurisdicción, cuestiones sobre deudas y pagos, cuestiones protocolarias y de precedencia.

- Vida cotidiana: excepcionales (injuria, violencia y sexo) y normales (medicina, alimentación, vivienda, vestidos, oficios, servicios, transportes o herencias).

- Instituciones vinculadas: cárcel del Estudio.

- Otros: Fuero universitario salmantino.

No obstante, los trabajos sobre las líneas propuestas quedan supeditados a las labores de catalogación de la Audiencia Escolástica, durante tantísimo tiempo paralizadas, y que

(1590-1625): el hospedaje (bachilleres de pupilos)» en El pasado histórico de Castilla y León. Vol. II. Edad Moderna. $1^{\text {a }}$ ed. Burgos: Junta de Castilla y León, 1983, pp. 187-199; del mismo autor, "Pupilajes, gobernaciones y casas de estudiantes en Salamanca (1590-1630)» en Studia Histórica. Historia Moderna, Vol. I, no 3, 1983, pp. 185-210; RODRÍGUEZ CRUZ, Águeda M. «Las oposiciones a cátedra en la Universidad de Salamanca y en las universidades hispanoamericanas: Época Moderna» en Historia de la Educación. Revista Interuniversitaria, no 3, 1984, pp. 7-26; PEREZ SAMPER, María Ángeles. La alimentación en la España del Siglo de Oro. Libro del Arte de Cocina de Domingo Hernández de Mancera, cocinero del Colegio Mayor de Oviedo de la Universidad de Salamanca, 1607. $1^{\text {a }}$ ed. Huesca: La Val de Onsera, 1998. 
ponen de relevancia no solo la importancia del trabajo del personal del archivo, a quienes agradezco la ayuda prestada, sino de la necesidad de seguir invirtiendo en la conservación e investigación de nuestro patrimonio histórico.

En un momento en que la autonomía universitaria es uno de los temas centrales en el futuro de las universidades públicas, el estudio de la historia y de los agentes o personas que la hacen posible, hace que las posibilidades de estudio que ofrecen los fondos de la Audiencia Escolástica del Archivo Universitario Salmantino cobren un renovado interés.

\section{ANEXO DOCUMENTAL}

Archivo Universitario Salmantino. Fondo: Audiencia Escolástica. Serie: Expedientes Judiciales. Número de catalogación: 1. Signatura: AUSA 2999. Fecha. 1547-1566. Caja 1, carpeta 13. 1562. Contiene el pleito entre el licenciado Meneses y el maestro Cuadrado, sobre hora de lectura, resuelto a favor del licenciado Meneses; y el pleito entre el licenciado Meneses y bachiller de la Torre, sobre hora de lectura, resuelto a favor del bachiller de la Torre. Transcripción de los fragmentos referidos a este segundo pleito ${ }^{25}$ :

[fol. 5, r.]Muy ilustre señor.

El maestro de la Torre ante vuestra merced parezco y digo que abra un año poco mas o menos que la universidad me hizo merced de sacarme de la regentia que tenia y darme una cathedra a la ora mas desocupada que se pudo hallar donde yo a nadie hiziese perjuicio ni nadie a mi, que es de cinco a seys, y aunque el intento de la universidad fue este que ni yo a nadie estorvase ni nadie a mi con todo eso el licenciado Meneses desde quatro meses a esta pare siempre sale a leer en mi competentia de cinco a seys perturbando mi auditorio y quebrando los estatutos que esta universidad tiene establecidos en esta facultad de grammatica lo cual hallara vuestra merced ser ansi verdad porque siendo rector el ilustre señor don Diego de Avila se hizo estatuto que fuera de las lectiones que la universidad tiene asignadas nadie leyese otras sino fuese de fiestas del qual estatuto a vuestra merced decir que a esa ora de cinco a seys otros an leydo de cinco a seys porque los tales lectores lo uno no podran leer y lo otro no abra entonces cathedratico en aquella ora, yo lo soy aora ni obsta decir que es lection provechosa la que el licenciado Meneses lee porque no es menos provechosa la de los otros que la suya, y si el a mi hora me a de alterar supplico a vuestra merced de licencia para que yo lea también en competentia de la suya y de los demas [tachado: si la] [fol. 5, v.] la qual licencia si de vuestra merced me fuere concedida protesto de usar della, aunque es verdad que la universidad viendo que

25 La transcripción sigue las normas de editadas por la Escuela de Estudios Medievales del Consejo Superior de Investigaciones científicas en 1944. 
la copia de muchas lectiones a los estudiantes le era dańosa introduxo la costumbre y ley que ante vuestra merced allego y tengo allegada para lo qual la justicia y favor de vuestra merced imploro y pido las costas.

El maestro de la Torre.

[fol. 6, r.] Muy ilustre señor.

Respondiendo a una petition puesta por el bachiller de la Torre digo que es falsedad que al dicho bachiller de la Torre se le hizo merced de le quitar de la regentia que tenia attento a que era ciego y cansado y que no podía ya leer [tachado: y] ni hazer el officio de grammatico preguntando, acotando y otras cosas que se requieren y le mandaron que leyese a ora que no estorvase los collegios y regentes ordinarios de la dicha facultad, pero no hay estatuto que prohiba que otros no lean a su hora lo qual provare.

Yten que yo hago lo que el no puede, gran exercitio preguntando, castigando, haciendoles hablar en latin y finalmente hago de tal manera mi officio que en este tiempo tengo quinientos oyentes y protesto de probar que ninguno en mi facultad en Salamanca ni Alcala ni en otras universidades aunque sean de fuera de nuestros reynos haze mas provecho que yo en esta facultad, y que attento al bien común [tachado: no se] pido vuestra merced no consienta que no haziendole yo detrimento ni prejuicio pierdan tantos hombres de ser enseñados.

Yten que es verdad que esta merced que se le hizo no fue para que quando yo sali a schuelas el no tenía oyentes y [tachado:ten] que aquel estatuto que hizo el señor don Diego de Avila no se hizo sino para que no se perturbasen los collegios y lectiones de prima y visperas que son lectiones que no se pueden escusar y la suya haze poco al caso que como a hombre jubilado se la [sic: se la] [fol. 6, v.] mandaron leer no tanto por el provecho que della resultava a los estudiantes, quanto por le hazer merced y dalle de comer.

Yten que otros an leydo a la mesma hora y no lo a estorvado paresce que ahora lo quiere estorvar por malicia y por ver que yo tengo tantos oyentes, y si es verdad que su liction es tan provechosa como la mia, vease en los oyentes exercitios y desto sean examinados los testigos. Supplico a vuestra merced que attento el provecho que yo hago y que no le estorvo ni le hago prejuicio, mande que yo ni mi auditorio sea perturbado, porque de otra manera es hazer mal y daño a grandisimo numero de hombres a los quales es el intento desta universidad aprovechar para lo qual la justicia y favor de vuestra merced imploro y pido las costas.

El licenciado Meneses.

[fol. 8, r.] Muy ilustre señor. 
El bachiller Diego de la Torre ante Vuestra Merced parezco y de mas del statuto que en defensa de mi justitia ante Vuestra Merced alegado tengo como en otro scripto mio antes deste contenido digo que allende de que el licenciado Meneses a encurido en graves penas conforme a el lo vi que tracta de las lecturas de mas desto digo que de mas de periudicar me a mi hora periudica a los colegios de grammatica porque estando le asignada a los regentes de nueve a diez las epistolas de julio donde los studiantes an de aconcurrir a oirlas para que con ellos se tenga cuenta conforme a estructiones, el dicho licenciado Meneses lee las mesmas epistolas de julio en escuelas donde los estudiantes concurren muchos por ser en escuelas y por vivir exemptos de la cuenta que deven dar a sus maestros y ansi a la hora de nueve a diez saltan en los colegios donde sus preceptores por que echan cuenta que de cinco a seys tienen la mesma lection y en escuelas de lo qual me quexo ante Vuestra Merced y pido justitia ansi por el mal particular que a mi me hace como por el daño publico que de aqui resulta a la orden de los colegios de grammatica desta universidad.

El bachiller Diego de la Torre.

[fol. 8 v.] Salamanca.

Visto por nos, don Pedro Manrique, lugarteniente del Rector del estudio e universidad de Salamanca por el ilustre señor don Antonio Manrrique, my hermano rrector en el dicho estudio, etc., este dicho pleyto e causa entre las dichas partes, fallamos que deviamos mandar e mandamos quel dicho licenziado Meneses no leyendo el mismo libro que lehe el bachiller Diego de la Torre, guardando la forma de los estatutos que disponen a açerca de los que quieren leher liçiones extrahordinarias y dando conforme a ellos sus fianças puede leher a la misma hora quel dicho [tachado: maestro] bachiller de la Torre atento lo que se açe en esta universidad y estudio de Salamanca en las horas de otras catedras mas calificadas. Fecha en nueve de jullio de mill e quinientos e sesenta e dos ańos. E ansi lo pronunçiamos e mandamos en estos scriptos e por ellos e lo firmamos. Va testado do deçia, maest, no vala.

Don Pedro Manrique (Rubricado). El doctor Juárez (Rubricado)

\section{FUENTES Y BIBLIOGRAFÍA}

Archivo Universitario Salmantino (AUSA). Fondo: Audiencia Escolástica. Series: Expedientes Judiciales y Autos Judiciales. Signatura: AUSA 2999 a AUSA 3678,5 .

ALONSO ROMERO, Ma . Paz. «Teoría y praxis en la enseñanza del derecho: tratados y prácticas procesales en la Universidad de Salamanca a mediados 
del siglo XVI». En Anuario de historia del derecho español. Documentos para la historia del derecho español. Madrid: Ministerio de Justicia, 1991. pp. 451-547.

- Universidad y sociedad corporativa. Historia del privilegio jurisdiccional del estudio salmantino. 1a Ed. Madrid: Technos, 1997.

ÁLVAREZ FERNÁNDEZ, Manuel; ROBLES CARCEDO, Laureano; RODRÍGUEZ-SAN PEDRO BEZARES, Luis Enrique. La Universidad de Salamanca. I. Historia y Proyecciones. II. Docencia e investigación. III. Arte y Tradiciones. $4^{\mathrm{a}}$ ed. [1 ${ }^{\mathrm{a}}$ ed. de 1972]. Salamanca: Ediciones Universidad de Salamanca, 1989, 1990, 1990.

CARABIAS TORRES, Ana María. «La Universidad de Salamanca en la Edad Moderna» en MARTÍN, José Luis (Dir.) Historia de Salamanca. t. III. Edad Moderna. coord. Por Ángel Rodríguez. $1^{\mathrm{a}}$ ed. Salamanca: Centro de Estudios Salmantinos, 1999. pp. 375-474.

- «La legislación universitaria en el siglo XVI» en Revista Española de Derecho Canónico, vol. 43, no 120, 1986, pp. 101-120.

CARABIAS TORRES, Ana María; LORENZO PINAR, Francisco Javier y MOLLER RECONDO, Claudia. Salamanca: Plaza y Universidad. $1^{\mathrm{a}} \mathrm{ed}$. Salamanca: Universidad de Salamanca, 2005.

CORTÉS VÁZQUEZ, Luis. La vida estudiantil en la Salamanca clásica a través de los textos. $1^{\mathrm{a}}$ ed. Salamanca: Universidad de Salamanca, 1985.

HALEY, George. Diario de un estudiante de Salamanca. La crónica inédita de Girolamo da Sommaia (1603-1613). Edición e introducción de George Haley. $1^{a}$ ed. Salamanca: Universidad de Salamanca, 1977.

HERNÁNDEZ SANDOICA, Elena. Tendencias historiográficas actuales. Escribir historia hoy. 1a ed. Madrid: Akal, 2004.

JUSTO SERNA, Alonso y Anaclet Pons. «La microhistoria: instrucciones de uso» en Cómo se escribe la microhistoria: ensayo sobre Carlo Guinzburg. 1 ${ }^{a}$ Ed. Madrid: Cátedra, 2000. pp. 231-273.

MARCOS RODRÍGUEZ, Florencio. «Un pleito de don Pedro Calderón de la Barca estudiante en Salamanca» en Revista de Archivos, Bibliotecas y Museos, LXVII, 2, 1959, pp. 717-731. 
PÉREZ SAMPER, María Ángeles. La alimentación en la España del Siglo de Oro. Libro del Arte de Cocina de Domingo Hernández de Mancera, cocinero del Colegio Mayor de Oviedo de la Universidad de Salamanca, 1607. 1a ed. Huesca: La Val de Onsera, 1998.

PESET, José Luis y HERNÁNDEZ SANDOICA, Elena. Estudiantes de Alcalá. $1^{a}$ ed. Madrid: Comisión de Cultura del Excmo. Ayuntamiento de Alcalá de Henares, 1983.

POUNDS NORMAN, J. G. La vida cotidiana: historia de la cultura material. $1^{\text {a }}$ Ed. en castellano. Barcelona: Crítica, 1992. [Herat and Home. A History of Material Culture. $1^{\text {a }}$ Ed. en inglés. Bloomington: Indiana University Press, 1989].

RODRÍGUEZ CRUZ, Águeda M. Historia de la Universidad de Salamanca. $1^{a}$ ed. Salamanca: Fundación Ramón de Areces-Congregación de Santo Domingo, 1990.

- "Las oposiciones a cátedra en la Universidad de Salamanca y en las universidades hispanoamericanas: Época Moderna» en Historia de la Educación. Revista Interuniversitaria, no 3, 1984, pp. 7-26.

RODRÍGUEZ-SAN PEDRO BEZARES, Luis Enrique. Atmósfera universitaria en Cervantes. $1^{a}$ ed. Salamanca: Universidad de Salamanca, 2006.

— «Vida estudiantil en el Antiguo Régimen» en Miscelánea Alfonso IX, 2001. Centro de Historia Universitaria. Salamanca: Universidad de Salamanca, 2002, pp. 69-96.

- Vida, aspiraciones y fracasos de un estudiante de Salamanca: el diario de Gaspar Ramos Ortíz, 1568-1569. 1ª ed. Salamanca: Universidad de Salamanca, 1987.

- «Estudiantes en Salamanca (1590-1625): el hospedaje (bachilleres de pupilos)» en El pasado histórico de Castilla y León. Vol. II. Edad Moderna. $1^{\text {a }}$ ed. Burgos: Junta de Castilla y León, 1983, pp. 187-199.

— «Pupilajes, gobernaciones y casas de estudiantes en Salamanca (1590-1630)» en Studia Histórica. Historia Moderna, Vol. I, no 3, 1983, pp. 185-210.

RODRÍGUEZ-SAN PEDRO BEZARES, L. E. y POLO RODRÍGUEZ, J. L. (coords.) Historia de la Universidad de Salamanca. Vol. I. Trayectoria histórica e instituciones vinculadas. Vol. II. Estructuras y flujos. Vol. III. 1 y 2 Saberes y confluencias. Vol. IV. Vestigios y entramados. $1^{\text {a }}$ ed. Salamanca: Universidad de Salamanca: 2002, 2004, 2006 y 2009. 
RODRÍGUEZ-SAN PEDRO BEZARES, Luis Enrique y WERUAGA PRIETO, Ángel. Elogios triunfales. Orígenes y significado de los vitores universitarios salmantinos (ss. XV-XVIII). $1^{\text {a }}$ ed. Salamanca: Universidad Pontificia de Salamanca, 2011.

TORREMOCHA HERNÁNDEZ, Margarita. «Nuevos enfoques en la historia de las universidades: la vida cotidiana de los universitarios en la península ibérica durante la Edad Moderna» en Chronica Nova, no 35, 2009, pp. 193-219.

- La vida estudiantil en el Antiguo Régimen. $1^{\text {a }}$ ed. Madrid: Alianza, 1998.

RUÍZ TORRES, Pedro (coord.). Doctores y escolares. II Congreso Internacional de las Universidades Hispánicas (Valencia, 1995). Vol. I y II. $1^{a}$ ed. Valencia: Universitat de València, 1998.

Universidad de Salamanca: Servicio de Archivos. Memoria del Servicio de Archivos correspondiente al curso 2009-2010. p. 41. Disponible en: http://campus.usal.es/-memoria/0910/11_rectorado/11_7_archivo_universitario.pdf [consultado 14/04/2012]. 